suspended in the hemilithotomy position. The operation lasted 1.75 hours and was completed satisfactorily. Next morning the patient complained of intense burning discomfort in the foot and leg of the unoperated limb. The power of ankle dorsiflexion was only MRC grade 4 . Over the next 36 hours the pain resolved and full power of dorsiflexion returned.

Discussion. Closed nailing is now the treatment of choice for closed femoral shaft fractures (Winquist, Hansen and Clawson 1984). The standard position for the patient on the operating table, with both legs extended, may not allow a clear fluoroscopic view of the upper shaft or of basal cervical fractures. We therefore placed the nonoperated leg in the hemilithotomy position, which resulted in excessive traction on the sciatic nerve. Fortunately in both our patients the injuries recovered quickly, with no permanent disability.

Common peroneal nerve palsy is recognised to result from local pressure from lithotomy strap supports (Leff and Shapiro 1979), and particular care was taken in both our patients to avoid such an injury. We believe that sciatic palsy has not been reported after a period in the unilateral lithotomy position previously. Compartment syndrome in the calf has been associated with the prolonged use of the hemilithotomy position (Dugdale et al 1989). In our cases flexion of one hip at $90^{\circ}$ with less than $90^{\circ}$ flexion at the knee may have stretched the sciatic nerve, pelvic rotation being prevented by the extension of the contralateral leg. The ipsilateral sciatic nerve can of course be damaged during closed femoral nailing (Britton and Dunkerley 1990) but we believe ours is the first report of contralateral sciatic nerve palsies.

No benefits in any form have been received or will be received from a commercial party related directly or indirectly to the subject of this article.

\section{REFERENCES}

Britton JM, Dunkerley DR. Closed nailing of a femoral fracture followed by sciatic nerve palsy. J Bone Joint Surg [Br] 1990; 72B:318.

Dugdale TW, Schutzer SF, Deafenbaugh MK, Bartosh RA. Compartment syndrome complicating the use of the hemi-lithotomy position during femoral nailing: a report of two cases. J Bone Joint Surg [Am] 1989; 71-A:1556-7.

Lefi RG, Shapiro SR. Lower extremity complications of the lithotomy position: prevention and management. J Urol 1979; 122:138-9.

Winquist RA, Hansen ST Jr, Clawson DK. Closed intramedullary nailing of femoral fractures: a report of five hundred and twenty cases. J Bone Joint Surg [ Am] 1984; 66-A :529-39.

\title{
UPPER TIBIAL VALGUS OSTEOTOMY USING A DYNAMIC EXTERNAL FIXATOR
}

\author{
J. L. FOWLER, G. A. GIE, A. G. MACEACHERN
}

Upper tibial valgus osteotomy has its difficulties and complications, including peroneal nerve palsy and vascular impairment when external fixation devices have penetrated the anterior compartment (Coventry 1985). Gibson et al (1986) found a singificant increase in compartment pressure in seven of ten closing wedge osteotomies which were not drained; this pressure increase or direct damage to the peroneal nerve may produce the palsy. Fibular osteotomy may cause paralysis of the extensor hallucis longus.

We have used since 1983 a method of osteotomy, as described by Turi et al (1987) which uses a single-bar dynamic axial fixator and a medially-based opening wedge corticotomy. This appears to reduce the risk of these complications.

J. L. Fowler, FRCS, Senior Orthopaedic Registrar

G. A. Gie, FRCS, Senior Orthopaedic Registrar

A. G. MacEachern, FRCS, Consultant Orthopaedic Surgeon

Princess Elizabeth Orthopaedic Hospital, Wonford Road, Exeter, Devon EX2 4UE, England.

Correspondence to Mr A. G. MacEachern.

(C) 1991 British Editorial Society of Bone and Joint Surgery

0301-620X/91/4R91 \$2.00

J Bone Joint Surg [ Br] 1991 ; 73-B : 690-1.
Technique. Under tourniquet and radiographic control, two or three tapered self-tapping cancellous screws are placed in the medial cortex of the upper tibia midway between the planned corticotomy site and the plateau. Two cortical screws are inserted distally.

A longitudinal incision is made just medial to the tibial tubercle and the cortex is cut, leaving the medulla and the lateral third of the cortex intact. To achieve this, cortical drill holes are made, and the osteotomy completed with a cement-splitting chisel. The fibula and the lateral compartment are not disturbed. An articulated fixator (Orthofix, Verona, Italy) is then attached and distracted to demonstrate opening of the osteotomy. It is then locked with the corticotomy in its closed position (Fig. 1). The wound is closed.

Early weight-bearing is encouraged. At about 14 days, when early callus has formed, the wedge is opened by distracting the fixator gradually at a rate of $1 \mathrm{~mm}$ per day until the correct alignment is obtained (Fig. 2). When radiographs show good callus formation, the locking nut is released and dynamic loading started. The fixator is removed when union is sound (Fig. 3).

Results. Of 31 upper tibial osteotomies performed by this technique, the first 21 were reviewed at an average follow-up of 14 months. These short-term results show 


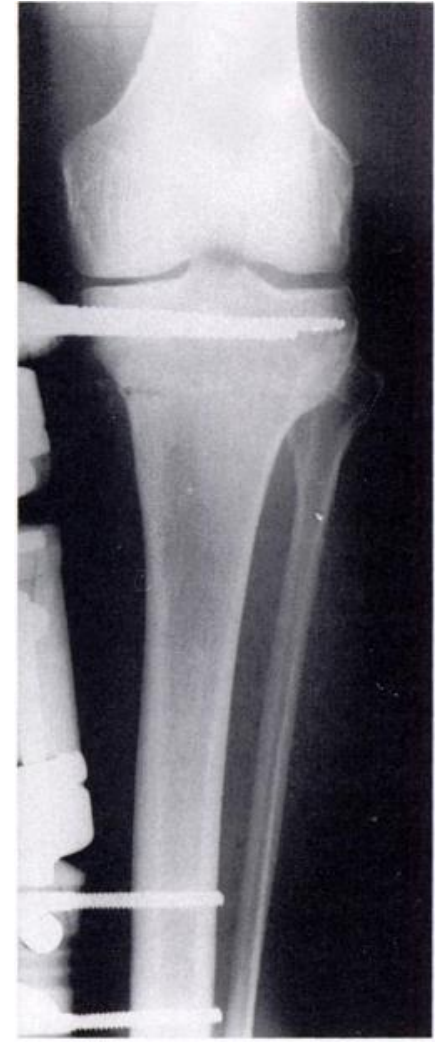

Fig. 1

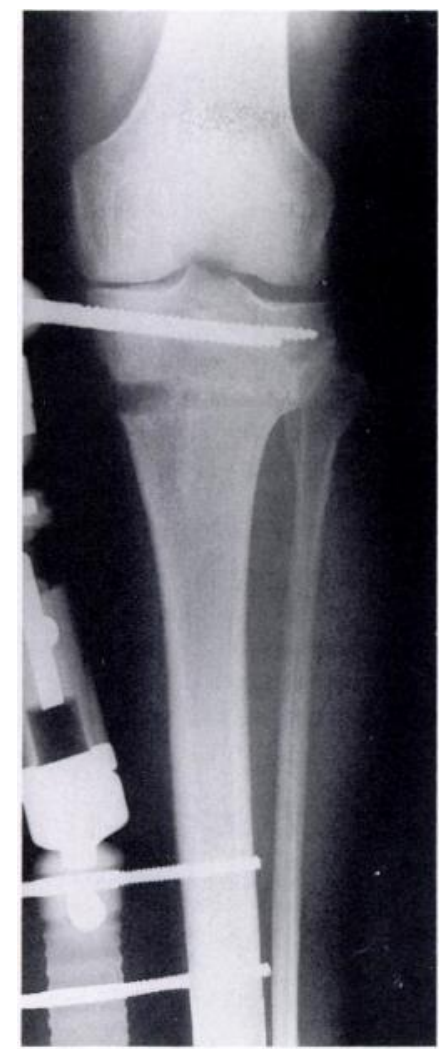

Fig. 2

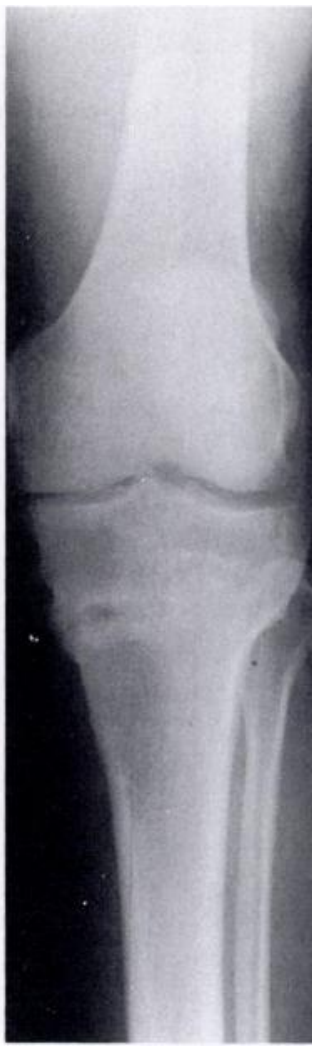

Fig. 3
Figure 1 - Postoperative, before distraction. Figure 2 - Distraction completed, satisfactory alignment. Figure 3 - Sound union, fixator removed. that 14 patients were pain free and six considerably improved. The average time to removal of the fixator was 13 weeks.

Complications have been few: no patient has developed a peroneal nerve palsy, but one patient failed to follow the distraction regime and the osteotomy united in its original position. No fixator required removal, though half the patients needed a course of antibiotics for pin-site inflammation. No ring sequestrae were seen.

In seven cases, anterior compartment pressure, monitored by a continuous effusion technique, remained below $30 \mathrm{mmHg}$ for 48 hours postoperatively.

Discussion. Upper tibial valgus osteotomy normally requires an exact correction, measured beforehand and maintained during healing. This new method is simple, needs only a small medial incision and appears to reduce the chance of nerve and vascular damage. Correction is by postoperative distraction and the alignment can be assessed with the patient weight-bearing, while early knee movement is easy. The method employs callus distraction, so bone grafting is not required. We have not observed early collapse of the new wedge of bone.

In addition, there is little of the disruption of the trabecular pattern of the proximal tibia seen after a closing-wedge operation (Windsor, Insall and Vince 1988); the method seems preferable for patients who may need total knee replacement later.

One or more of the authors have received or will receive benefits for personal or professional use from a commercial party related directly or indirectly to the subject of this article.

\section{REFERENCES}

Coventry MB. Current concepts review. Upper tibial osteotomy for osteoarthritis. J Bone Joint Surg [ Am] 1985; 67-A:1136-40.

Gibson MJ, Barnes MR, Allen MJ, Chan RNW. Weakness of foot dorsiflexion and changes in compartment pressures after tibial osteotomy. J Bone Joint Surg [Br] 1986; 68-B:471-5.

Turi G, Cassini M, Tomasi PS, Armotti P, Lavini F. L'osteotomia direzionale di ginocchio mediante la "emicallotasi". Chir Organi Mov 1987; 72(3):205-9.

Windsor RE, Insall JN, Vince KG. Technical considerations of total knee arthroplasty after proximal tibial osteotomy. J Bone Joint Surg $[\mathrm{Am}]$ 1988; 70-A :547-55. 